\title{
Characterization of Fertile Homozygous Genotypes from Anther Culture in Apple
}

\author{
Hatsuhiko Okada, Yoshitaka Ohashi, and Mamoru Sato ${ }^{1}$ \\ Fruit Tree Research Centre, Fukushima Agricultural Technology Centre, Fukushima 960-0231, \\ Japan
}

Hideyuki Matsuno

Agricultural College, Fukushima Agricultural Technology Centre, Yabuki, Fukushima 969-0292, Japan

Toshiya Yamamoto and Hoytaek Kim

National Institute of Fruit Tree Science, Tsukuba, Ibaraki 305-8605, Japan

Tatsuro Tukuni

Chiba Prefectural Agriculture and Forestry Research Center, Midori-ku, Chiba 266-0006, Japan

Sadao Komori

Department of Agro-Bioscience, Faculty of Agriculture, Iwate University, Morioka, Iwate 020-8550, Japan

Additional INDEX WORDS. androgenesis, doubled haploids, flow cytometry, Malus $\times$ domestica, morphology, SSR analysis, $S$-allele

\begin{abstract}
Doubled haploids can improve the efficiency of breeding and genetic study in apple (Malus $\times$ domestica Borkh.). Seventeen homozygous genotypes were obtained by in vitro anther culture from 'Senshu' apple. Flow cytometry analysis revealed that the ploidy level of the anther-derived plantlets was diploid. Simple sequence repeat (SSR) analysis determined the origin and homozygous status of the anther-derived plantlets. The results of $S$-RNase polymerase chain reaction (PCR)-digestion analysis reinforced the homozygous state. The morphological characteristics and reproductive potential of the doubled haploids were investigated. It is especially interesting that one of the doubled haploids derived from anther culture had fertile pollen grains (rate of in vitro germination was $20.6 \%-$ $33.0 \%$ ), and several progenies were obtained from the cross between 'Prima' apple and the doubled haploid. The hybridism of these seedlings was confirmed by SSR analysis. Furthermore, the female gametes of the doubled haploid showed slight fertility. Thus, this doubled haploid will be valuable for breeding and genetic studies.
\end{abstract}

The obstacles to breeding programs and genetic analysis in apple are the long reproductive cycle with a juvenile phase that lasts several years, the highly heterozygous nature of the genome, the large canopy size, and self-incompatibility that generally prevents inbreeding and promotes out-crossing. As homozygosity can reduce the number of genetic recombinations occurring in the progeny of a cross, a better understanding of the genetic control of characteristics would be possible by using homozygous genotypes as the parents. Therefore, homozygous genotypes would offer new possibilities for breeding and genetic studies in apple and would facilitate the search for molecular markers related to important agronomic characteristics. In the 1970s, the first approaches were conducted to produce doubled haploids in apple by in vitro anther culture (Nakayama et al., 1972). Since then, various homozygous genotypes induction methods such as in vitro anther culture and in situ parthenogenesis in apple have been reported (De Witte, 2000; Hidano, 1982; Höfer, 2004; Höfer and Hanke,

Received for publication 14 Apr. 2009. Accepted for publication 25 Nov. 2009. This study was supported through the promotion of research and development projects for application in promoting new policy of Agriculture, Forestry, and Fisheries (no. 18094) from the Ministry of Agriculture, Forestry and Fisheries of Japan.

${ }^{1}$ Corresponding author. E-mail: satou_mamoru_01@pref.fukushima.jp.
1990; Kadota et al., 2002; Lespinasse et al., 1999; Zhang and Lespinasse, 1991). Although the number of technical methods for inducing homozygous genotypes has increased, information on the morphological characterization of doubled apple haploids is rather limited.

In recent years, several homozygous apple plants have flowered (De Witte, 2000; Höfer et al., 2004, 2008; Lespinasse et al., 1999; Okada et al., 2006; Vanwynsberghe et al., 2005). In other perennial species [e.g., a haploid plant from a female gamete of 'Banpeiyu' pumelo (Citrus grandis Osbeck)], fertile pollen grains have been reported (Yahata et al., 2005). However, homozygous apple plants have had extremely low pollen fertility, with the exception of the results from Höfer et al. (2008) obtained by in situ parthenogenesis.

In our previous study (Matsuno et al., 1996), several homozygous genotypes were obtained by in vitro anther culture from 'Senshu' apple. These genotypes were grafted onto an apple rootstock in the field, and 2 to 4 years after grafting, three of the genotypes produced several flowers for the first time.

The objectives of the present study were to confirm the ploidy level of the androgenic genotypes by flow cytometry; to confirm the zygosity state of the androgenic genotypes by SSR markers; to analyze $S$-alleles of the androgenic genotypes by the specific polymerase chain reaction (PCR)-digestion method; and to compare the morphological characteristics and pollen 
fertility of the androgenic genotypes and their donor genotype 'Senshu'. Furthermore, the reproductive potential of the androgenic genotypes was evaluated.

\section{Materials and Methods}

Plant material. Androgenic plant materials obtained between 1992 and 1995 from in vitro culture of anthers of 'Senshu' apple (Matsuno et al., 1996) were used in the present study. 'Senshu' was originated from the cross of 'Toko' $\times$ 'Fuji' at the Akita Fruit Tree Experiment Station in Japan. It matures in later mid-September. Skin color is bright striped red, flesh is crisp and juicy, and the quality is excellent. The androgenic plant materials were grafted onto a 'JM7' apple rootstock (Yoshida et al., 1997) and were planted in the field at the Fukushima Fruit Tree Research Center. The donor genotype of the androgenic plant materials, 'Senshu', was used as the control.

Ploidy analysis. The ploidy level of sampled plants was determined by flow cytometry. Fresh leaves were collected from the androgenic genotypes in the field. Collected leaves were cut into $0.5-\mathrm{mm}$ squares and chopped with a razor blade in a nuclei extraction buffer (Solution A of the High Resolution Kit for Plant DNA; Partec, Münster, Germany). After filtration through a 30- $\mu \mathrm{m}$ CellTrics ${ }^{\circledR}$ disposable filter (Partec), a staining solution (Solution B of the kit) was added. The mixture was analyzed using a PA flow cytometer (Partec). 'Jonagold' apple was used as the internal standard; it was known to be triploid (Janick et al., 1996). The results were displayed as a DNA histogram.

DNA extraction. Total DNA was extracted from the leaves of individual plants using the DNeasy Plant Mini Kit (QIAGEN, Hilden, Germany) following the manufacturer's instructions with slight modifications (Yamamoto et al., 2006).

CONFIRMATION OF ANTHER CULTURE-DERIVED PLANTLETS ASSESSED BY SIMPLE SEQUENCE REPEAT (SSR) MARKERS. Thirtyfive SSR markers were used for investigating the origin and zygosity state of the androgenic plants via anther culture (Table 1; Gianfranceschi et al., 1998; Liebhard et al., 2002). PCR amplification was performed in a $20-\mu \mathrm{L}$ solution of $10 \mathrm{~mm}$ Tris- $\mathrm{HCl}$ (pH 8.3), $50 \mathrm{~mm} \mathrm{KCl}, 1.5$ to $2.25 \mathrm{~mm} \mathrm{MgCl}_{2}, 0.01 \%$ gelatin, $0.2 \mathrm{~mm}$ each of dNTPs, $10 \mathrm{pmol}$ each of forward primer labeled with fluorescent dye (Fam/Tet/Hex or Fam/Vic/Ned) and unlabeled reverse primer, $10 \mathrm{ng}$ of genomic DNA, and 0.5 units of Taq polymerase (Invitrogen, Carlsbad, CA). The PCR profile consisted of initial denaturation for $4 \mathrm{~min}$ at $94{ }^{\circ} \mathrm{C}$ followed by 35 cycles of $1 \mathrm{~min}$ at $94{ }^{\circ} \mathrm{C}, 1 \mathrm{~min}$ at $50{ }^{\circ} \mathrm{C}, 2 \mathrm{~min}$ at $72{ }^{\circ} \mathrm{C}$, and a final extension of $4 \mathrm{~min}$ at $72{ }^{\circ} \mathrm{C}$.

The PCR products of each SSR locus were separated and detected using a PRISM 3100 DNA sequencer (Applied Biosystems, Foster City, CA). The size of the amplified bands was determined based on an internal standard DNA (GeneScan ${ }^{\text {TM }}$ 350-TAMRA or 400HD-ROX, Applied Biosystems) using GeneScan software (Applied Biosystems).

S-allele-SPeCific PCR-digestion analysis. PCR amplification was conducted using the $S$-RNase-specific primer combination ASPF3 and ASPR3, and PCR conditions were as described by Kim et al. (2006, 2008). The amplified S-RNase fragments were digested using the $S$-allele-specific restriction enzymes $M v a \mathrm{I}\left(S^{I}\right)$ and HindIII $\left(S^{7}\right)$ and were analyzed by agarose gel electrophoresis as described by Kim et al. (2009).

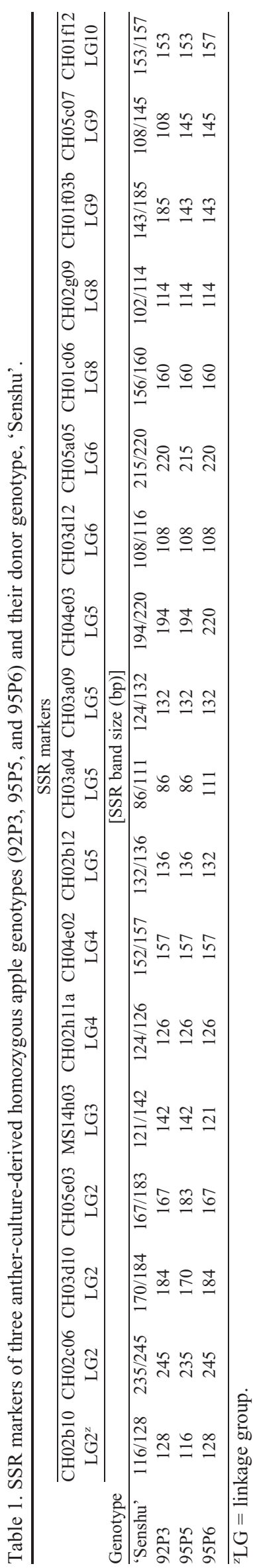


MoRPHOLOGICAL CHARACTERISTICS. For evaluation of several morphological characteristics of the androgenic genotypes and 'Senshu' apple, leaf length, leaf width, diameter of flower, and number of stamens and petals per flower were measured using 10 samples. For investigation of fruit quality, depending on yield, 8
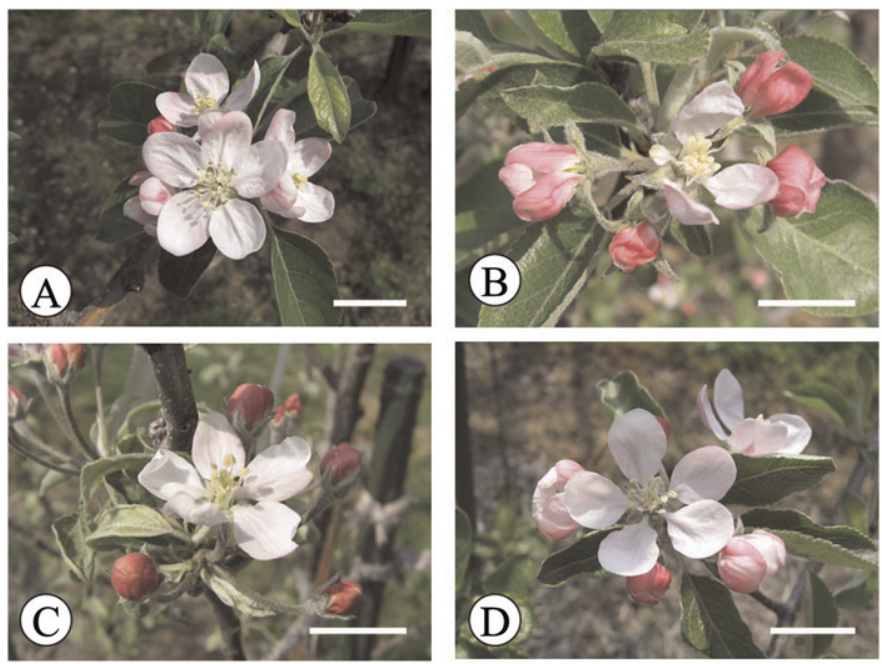

Fig. 1. Flower morphology of three androgenic apple genotypes (92P3, 95P5, and 95P6) and their donor genotype, 'Senshu'. (A) 'Senshu', (B) 92P3, (C) 95P5, (D) 95P6; bar $=20 \mathrm{~mm}$. to 10 apples per androgenic genotype were used. The source of the pollen used to produce the fruit was open pollinated. After measuring the diameter and weight of the fruit, the firmness of peeled fruit was tested by Magness-Taylor pressure tester (Fujiwara, Tokyo). Thereafter, soluble solids were measured using a digital refractometer (PR-101; Atago, Tokyo). Acidity was measured by titration with $\mathrm{NaOH}$ and was calculated as malic acid. In addition, seeds were extracted from the fruit and their size was measured. Data were subjected to analysis of variance by STATISTICA (version 03J; StatSoft, Tulsa, OK). Mean comparisons, except for soluble solids and acidity, were conducted using Tukey's multiple range test at $P=0.05$.

For the determination of seed viability, seeds were wrapped with moistened paper, placed in a polyethylene pack, and maintained at $5.5^{\circ} \mathrm{C}$ until sowing time.

Crossing for eVAluation of ReProductive potential. 'Prima' apple was used as the seed parent and androgenic homozygous genotype 95P6 was used as the pollen parent for the investigation of reproductive potential. The flowers were pollinated immediately after emasculation and were covered with paraffin paper bags. The fruit were collected at maturity and were maintained for 3 months at $4{ }^{\circ} \mathrm{C}$. The seeds were then extracted from the fruit and immediately planted in a $45-\mathrm{mL}$ cell tray $(72$ cells per tray), which were placed in a greenhouse. After germination, preliminary examination of the hybridism of about 10 of the seedlings was carried out by SSR analysis using CH03d10, MS14h03, CH02h11a, CH05c07, MS06g03, CH04d10, $\mathrm{CH} 05 \mathrm{~d} 11$, and $\mathrm{CH} 02 \mathrm{c} 09$. These eight SSR markers were used

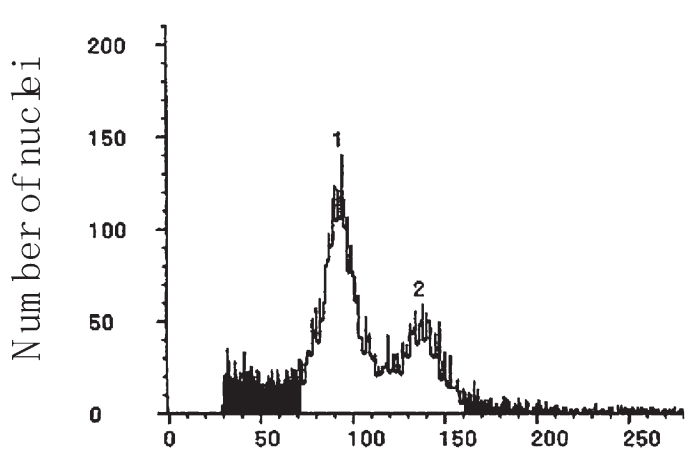

A Fluorescence intensity

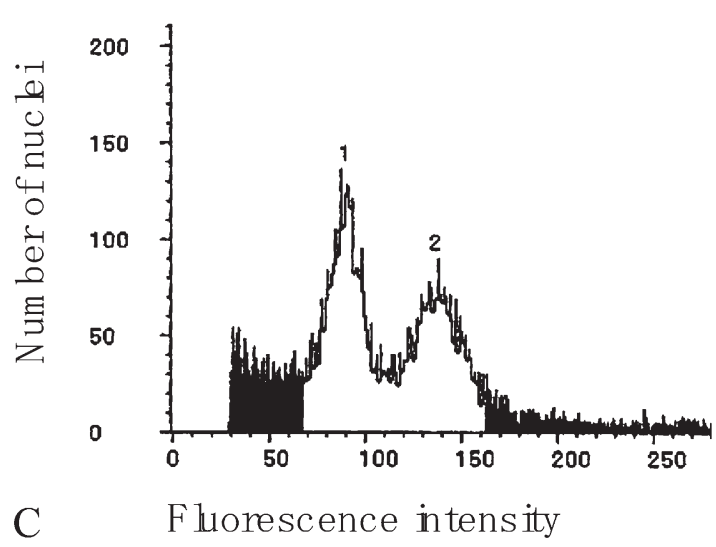

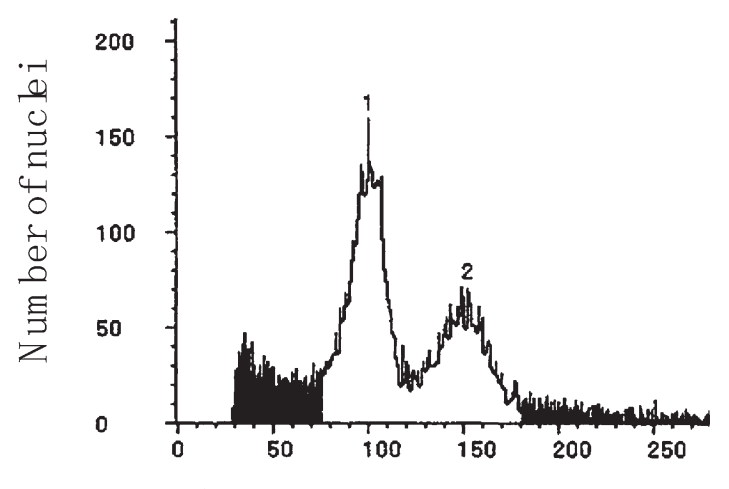

B Fluorescence intensity

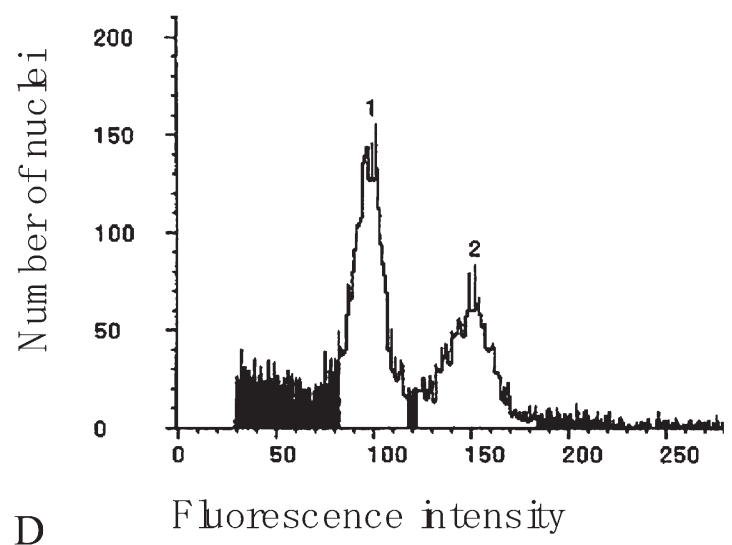

Fig. 2. Flow cytometry analysis of leaves in three androgenic apple genotypes (92P3, 95P5, and 95P6) and their donor genotype, 'Senshu'. (A) ‘Senshu', (B) 92P3, (C) 95P5, (D) 95P6. Peak 1 = 'Senshu' or the androgenic genotype; Peak $2=$ 'Jonagold'. 
to evaluate homozygous genotypes of anther culture-derived genotype 95P6, showed heterozygous genotypes for 'Prima' apple and were distributed in different linkage groups (LGs).

\section{Results and Discussion}

Androgenic Plantlets derived From anther CUlture in APPLE. Anther culture experiments that were carried out between 1992 and 2008 resulted in 17 androgenic genotypes. Although seven genotypes were dropped from the experiment during subculture and two genotypes were maintained in vitro, the other eight androgenic genotypes survived in the experimental field after planting and, moreover, only three of the eight androgenic genotypes flowered between 2002 and 2008, namely, genotypes 92P3, 95P5, and 95P6 (Fig. 1). These genotypes continued to flower each year after the first flowering.

Evaluation of Ploidy Level. Ploidy analysis by flow cytometry revealed that the fluorescence intensity of the flowered androgenic genotypes was two-thirds that of the triploid genotype 'Jonagold' apple (Fig. 2). This result showed that the flowered androgenic genotypes were diploid.

RESUlts of SSR ANALYSIS. In apples, SSR markers are used for molecular characterization and identification and for mapping (Gianfranceschi et al., 1998; Guilford et al., 1997; Kitahara et al., 2005; Silfverberg-Dilworth et al., 2006). SSR is also used for analyzing the genetic origin of haploid/diploid regenerants (Höfer et al., 2002, 2004, 2008; Kenis and Keulemans, 2000; Vanwynsberghe et al., 2005). In the present study, about 100 SSR markers (Gianfranceschi et al., 1998; Liebhard et al., 2002), whose positions were identified in apple genetic linkage maps, were tested for evaluation of anther culture-derived genotypes. Among them, 35 SSR markers showing heterozygous genotype for the donor genotype 'Senshu' were used for characterization of three anther culture-derived genotypes 92P3, 95P5, and 95P6 (Table 1). Thirty-five SSR markers used in this study were distributed in almost all LGs except for LGs 1,7,13, and 17. All alleles of the donor genotype were also found in the anther culture-derived genotypes, but only one

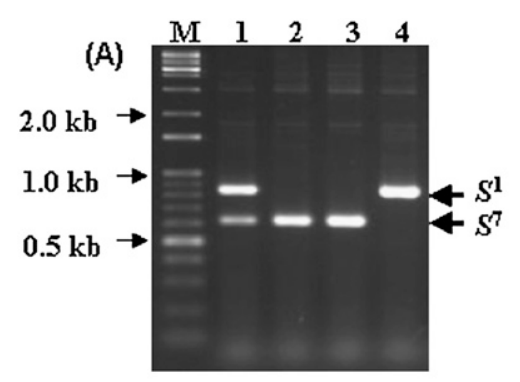

(B)

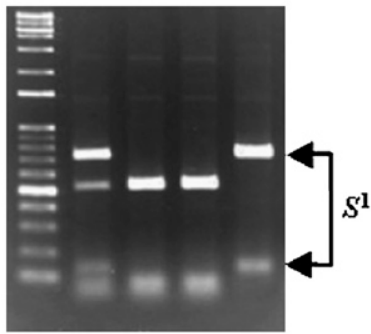

(C)

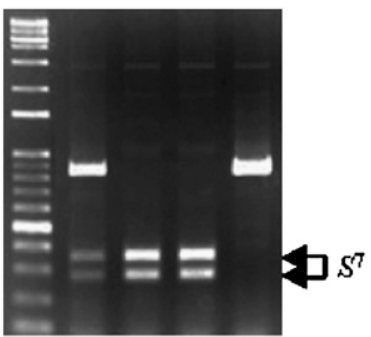

Fig. 3. S-RNase PCR-digestion analysis for identification of the homozygosity state and the $S$-genotypes of three androgenic apple genotypes (92P3, 95P5, and 95P6) and their donor genotype, 'Senshu'. The S-RNase fragments were amplified by PCR using ASPF3 and ASPR3 primers (A) and were digested with $S$-allele-specific restriction enzymes: $M v a \mathrm{I}\left(S^{1}\right)(\mathbf{B})$ and $\operatorname{HindIII}\left(S^{7}\right)(\mathbf{C})$. Line $1=$ 'Senshu'; line $2=92 \mathrm{P} 3$, line $3=95 \mathrm{P} 5$, line $4=95 \mathrm{P} 6$.

allele per locus was amplified in each sample. This indicates that all of the anther culture-derived genotypes have a haploid origin, although they are now diploid.

Table 2. Comparison of leaf morphological characteristics in three doubled haploids of apple (92P3, 95P5, and 95P6) and their donor genotype, 'Senshu'.

\begin{tabular}{lccccc}
\hline Genotype & $\begin{array}{c}\text { Leaf length } \\
{[\text { mean } \pm \mathrm{SD}(\mathrm{cm})]}\end{array}$ & $\begin{array}{c}\text { Leaf width } \\
{[\text { mean } \pm \mathrm{SD}(\mathrm{cm})]}\end{array}$ & $\begin{array}{c}\text { Length/width ratio } \\
{[\text { mean } \pm \mathrm{sD}]}\end{array}$ & $\begin{array}{c}\text { Petiole length } \\
{[\text { mean } \pm \mathrm{SD}(\mathrm{cm})]}\end{array}$ & $\begin{array}{c}\text { Petiole diam } \\
{[\mathrm{mean} \pm \mathrm{SD}(\mathrm{mm})]}\end{array}$ \\
\hline 'Senshu' & $9.1 \pm 1.0 \mathrm{a}^{\mathrm{z}}$ & $5.0 \pm 0.5 \mathrm{a}$ & $1.8 \pm 0.1 \mathrm{~b}$ & $2.4 \pm 0.2 \mathrm{a}$ & $1.9 \pm 0.2 \mathrm{a}$ \\
95P6 & $8.2 \pm 0.7 \mathrm{~b}$ & $3.9 \pm 0.4 \mathrm{bc}$ & $2.1 \pm 0.1 \mathrm{a}$ & $2.5 \pm 0.3 \mathrm{a}$ & $1.5 \pm 0.1 \mathrm{~b}$ \\
95P5 & $7.1 \pm 0.9 \mathrm{c}$ & $3.9 \pm 0.3 \mathrm{c}$ & $1.8 \pm 0.2 \mathrm{~b}$ & $1.7 \pm 0.3 \mathrm{~b}$ & $2.0 \pm 0.2 \mathrm{a}$ \\
92P3 & $8.0 \pm 0.5 \mathrm{~b}$ & $4.4 \pm 0.4 \mathrm{~b}$ & $1.8 \pm 0.2 \mathrm{~b}$ & $1.9 \pm 0.2 \mathrm{~b}$ & $1.6 \pm 0.1 \mathrm{~b}$ \\
\hline
\end{tabular}

${ }^{\mathrm{z}}$ Means in columns with different letters are significantly different via Tukey's test at $P=0.05$.

Table 3. Comparison of flower morphological characteristics in three doubled haploids of apple (92P3, 95P5, and 95P6) and their donor genotype, 'Senshu'.

\begin{tabular}{lcccccc}
\hline Genotype & Full bloom date & $\begin{array}{c}\text { Flowers } \\
{[\text { mean } \pm \text { SD }(\text { no./cluster })]}\end{array}$ & $\begin{array}{c}\text { Flower diam } \\
{[\text { mean } \pm \text { SD }(\mathrm{cm})]}\end{array}$ & $\begin{array}{c}\text { Petals } \\
{[\text { mean } \pm \text { SD }(\text { no. })]}\end{array}$ & $\begin{array}{c}\text { Stamens } \\
{[\text { mean } \pm \text { SD }(\text { no. })]}\end{array}$ & $\begin{array}{c}\text { Pistils } \\
{[\text { mean } \pm \text { SD }(\text { no. })]}\end{array}$ \\
\hline 'Senshu' & 30 Apr. & $5.1 \pm 0.7 \mathrm{ab}^{\mathrm{y}}$ & $4.3 \pm 0.4 \mathrm{a}$ & $5.0 \pm 0.0 \mathrm{a}$ & $19.4 \pm 1.1 \mathrm{NS}$ & $5.3 \pm 0.5 \mathrm{NS}$ \\
95P6 & 2 May & $5.6 \pm 0.8 \mathrm{a}$ & $3.9 \pm 0.2 \mathrm{ab}$ & $5.0 \pm 0.0 \mathrm{a}$ & $19.4 \pm 0.8$ & $5.0 \pm 0.0$ \\
95P5 & 2 May & $4.6 \pm 0.8 \mathrm{ab}$ & $3.6 \pm 0.2 \mathrm{~b}$ & $5.0 \pm 0.0 \mathrm{a}$ & $17.3 \pm 2.8$ & $5.3 \pm 0.5$ \\
92P3 & 4 May & $4.2 \pm 1.0 \mathrm{~b}$ & $3.6 \pm 0.5 \mathrm{~b}$ & $3.9 \pm 1.0 \mathrm{~b}$ & $17.2 \pm 2.5$ \\
\hline
\end{tabular}

${ }^{\mathrm{z}}$ Average date of 'Senshu' and 92P3 was investigated between 2003 and 2009; that of 95P6 and 95P5 was investigated between 2008 and 2009. ${ }^{y}$ Means in columns with different letters are significantly different via Tukey's test at $P=0.05$; ns means not significantly different within a column. 


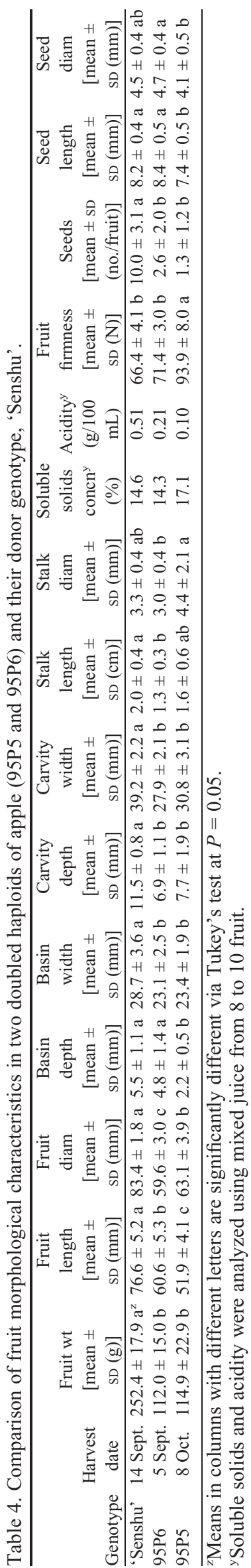

Results of $S$-allele analysis. Generally, diploid apple cultivars contain two different alleles of the $S$-gene and therefore the androgenic genotype induced by in vitro anther culture from the diploid cultivars should have only one of the alleles of the parent. Consequently, analysis of the $S$-alleles was a valuable approach for confirming their haploid origin (Verdoodt et al., 1998). In addition, the knowledge of the $S$-alleles was useful for cross-pollinating and genetic studies. In the previous study, the parental cultivar used was 'Senshu', which contained $S^{l} S^{7}$ alleles (Kitahara et al., 1997; Komori et al., 2000; Matsumoto et al., 1999; Sakurai et al., 1997). Using the $S$-RNase-specific primers (ASPF3 and ASPR3), the results of PCR analysis of 'Senshu' and the three flowered androgenic genotypes (92P3, 95P5, and 95P6) are shown in Fig. 3A. The PCR products $844 \mathrm{bp}\left(S^{I}\right)$ and $618 \mathrm{bp}\left(S^{7}\right)$ were amplified from
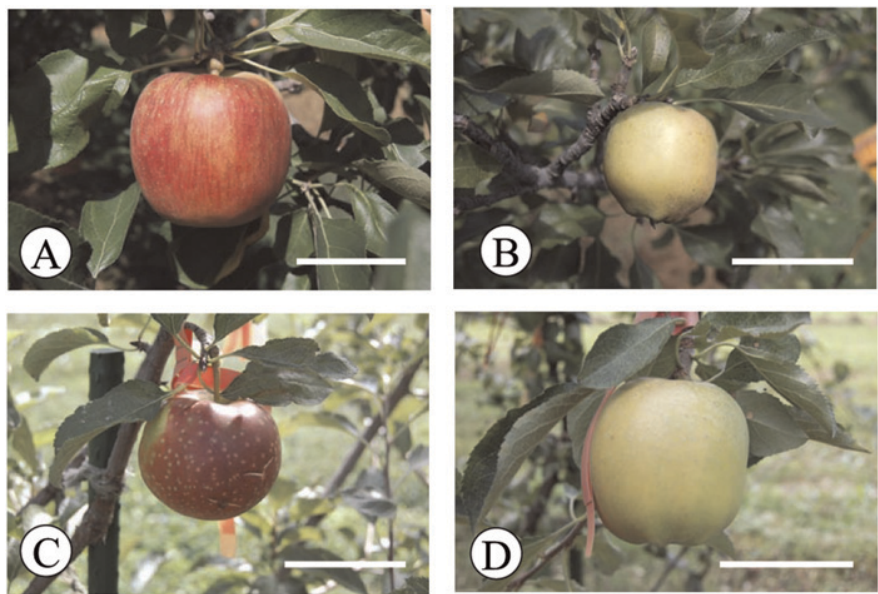

Fig. 4. Fruit of three androgenic apple genotypes (92P3, 95P5, and 95P6) and their donor genotype, 'Senshu'. (A) 'Senshu', (B) 92P3, (C) 95P5, (D) 95P6; bar $=50 \mathrm{~mm}$

Table 5. Rate of anther dehiscence and in vitro pollen germination at different developmental flower stage in three doubled haploids of apple (92P3, 95P5, and 95P6) and their donor genotype, 'Senshu'.

\begin{tabular}{llcc}
\hline Genotype & $\begin{array}{c}\text { Developmental } \\
\text { flower stage }\end{array}$ & $\begin{array}{c}\text { Anther } \\
\text { dehiscence } \\
(\%)^{\mathrm{y}}\end{array}$ & $\begin{array}{c}\text { In vitro } \\
\text { pollen } \\
\text { germination }(\%)^{\mathrm{x}}\end{array}$ \\
\hline 'Senshu' & Balloon & 78.3 & 82.9 \\
& Early bloom & 97.8 & 85.3 \\
& Middle bloom & 99.4 & 85.3 \\
95P6 & Balloon & 0.9 & 1.3 \\
& Early bloom & 20.6 & 20.6 \\
95P5 & Middle bloom & 68.9 & 33.0 \\
& Balloon & 0.0 & 0.0 \\
& Early bloom & 16.2 & 0.0 \\
92P3 & Middle bloom & 88.1 & 0.0 \\
& Balloon & 0.0 & 0.0 \\
& Early bloom & 0.0 & 0.0 \\
& Middle bloom & 94.1 & 0.0
\end{tabular}

${ }^{\mathrm{z}}$ Early bloom $=$ before dehiscence of anthers in the field, middle bloom $=$ after dehiscence of anthers in the field.

y Average number of anthers evaluated for 'Senshu', 95P6, 95P5, and 92P3 was $185,232,156$, and 164 , respectively.

'Average number of pollen grains evaluated for 'Senshu', 95P6, 95P5, and $92 \mathrm{P} 3$ was $383,472,117$, and 137 , respectively. 
'Senshu'. However, 92P3 and 95P5 obtained only the $S^{7}$ allele, and 95P6 obtained only the $S^{l}$ allele, respectively. The $S$-RNase PCR fragments were digested with the $S^{1}$ - and $S^{7}$-allele-specific restriction enzymes, MvaI $\left(S^{I}\right)$ (Fig. 3B) and HindIII $\left(S^{7}\right)$ (Fig. $3 \mathrm{C}$ ) to confirm the homozygosity state and $S$ genotypes of the three flowered androgenic genotypes. The 844-bp PCR fragments of 'Senshu' and 95P6 were cut with MvaI into two fragments of 712 and $132 \mathrm{bp}$ ( $S^{1}$-allele) and the 618-bp PCR fragments of 'Senshu', 92P3 and 95P5, were cut with HindIII into 343 and 275 bp ( $S^{7}$-allele). The $S^{1}$-specific enzyme MvaI was found to also digest the $S^{7}$-allele, yielding 505-, 82-, and 31-bp fragments from 'Senshu', 92P3, and 95P5. Therefore, the $S$ genotypes of 92P3, 95P5, and 95P6 were determined as $S^{7}, S^{7}$, and $S^{l}$, respectively, by the PCR-digestion analysis, suggesting that the three flowered androgenic genotypes (92P3, 95P5, and 95P6) were homozygous genotypes.

The previously described results confirmed that the flowered androgenic genotypes were probably doubled haploids. In general, polyploidization easily occurs during anther culture (Hidaka, 1984; Hidaka et al., 1982; Höfer et al., 2008; Kadota et al., 2002; Vanwynsberghe et al., 2005; Verdoodt et al., 1998). In the present study, doubled haploids were also induced without antimitotic agents such as colchicines. This phenomenon was described by Höfer et al. (2008). It is probable that the vigor of the doubled haploids' secondary embryos or cotyledons was higher than haploid tissues. Therefore, their aptitude for shoot regeneration and micropropagation is higher, and haploid structures were likely eliminated during the development.

Morphological CHARACTERISTICS. The morphological characteristics of the flowered doubled haploids were compared with those of 'Senshu'. The leaf length and width of doubled haploids were significantly smaller, whereas their shape, except for 95P6, was similar to that of 'Senshu' (Table 2). The shape of 95P6 seemed slight compared with the others. The petiole length of 95P5 and 92P3 was significantly shorter than that of 'Senshu' and 95P6. The petiole diameter of 95P6 and 92P3 was significantly thinner than that of 'Senshu' and 95P5.

The doubled haploids bloomed 2 to $4 \mathrm{~d}$ later than 'Senshu' (Table 3). 'Senshu' is one of the late-flowering commercial cultivars in Japan; therefore, the doubled haploids were regarded as the latest flowering and, when using them for examination of cross-pollination, attention must be paid to the season. The number of flowers per cluster of 95P6 and 95P5 did not differ significantly from that of 'Senshu', but 95P6 was significantly more than that of 92P3. 95P5 and 92P3 had significantly smaller flowers compared with 'Senshu'. 92P3 had a significantly reduced number of petals compared with 95P6, 95P5, and 'Senshu.' The number of stamens and pistils did not differ significantly. Aberrant flower morphology of androgenic genotypes obtained from in vitro culture of anthers of apple was described by Vanwynsberghe et al., (2005). On the other hand, seemingly normal flower aspects were reported by Höfer et al. (2008). In the present study, flower morphol$10 \mathrm{~cm})$. ogy of the flowered doubled haploids was separated between normal and aberrant. 95P6 was similar to that of the donor genotype 'Senshu' (Fig. 1D). 95P5 differed from 'Senshu' only in flower diameter (Fig. 1C). 92P3 had aberrant flower morphology, except the number of stamens and pistils (Fig. 1B).

Characteristics of Fruit. Table 4 show the results of observation on the fruit characteristics of doubled haploids, with the exception of 92P3, which had too small a yield for comparison with the others. Ripening time of 95P6 was earlier than 'Senshu', and that of 95P5 was later than 'Senshu'. The fruit color of 'Senshu' was a striped red type (Fig. 4A), whereas that of 92P3 and 95P6 was green-yellow (Fig. 4, B and D) and that of 95P5 was solid red (Fig. 4C). Thus, 'Senshu' was heterozygous for anthocyanin production. Although the study of all aspects of fruit color is complex (Janick et al., 1996), it is interesting that solid red occurred from striped red via anther culture. The fruit size of doubled haploids was significantly smaller than that of the donor genotype 'Senshu'. A similar
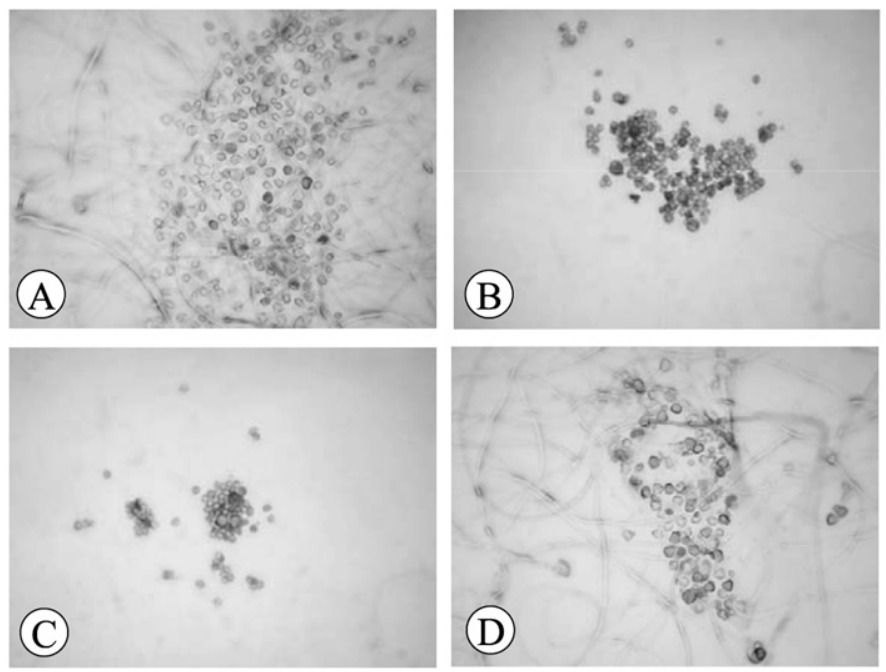

Fig. 5. In vitro pollen germination of three androgenic apple genotypes (92P3, 95P5, and 95P6) and their donor genotype 'Senshu'. (A) 'Senshu', (B) 92P3, (C) 95P5, (D) 95P6.
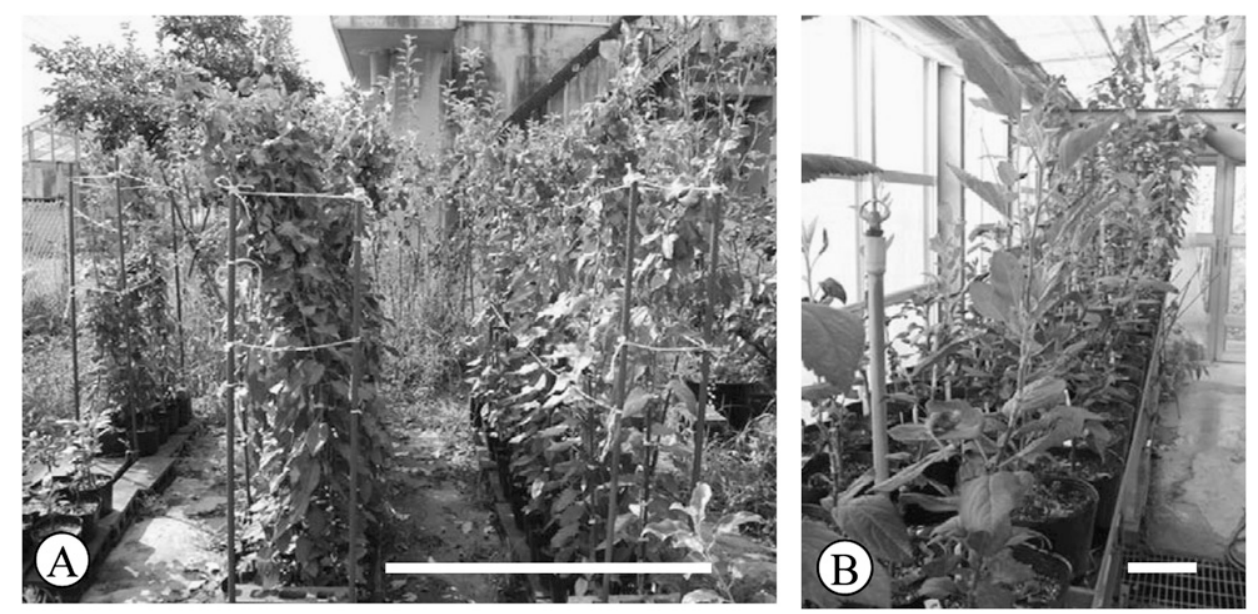

Fig. 6. The progenies obtained from cross between 95P6 and 'Prima' apple: (A) seedlings 7 months after germination (bar $=100 \mathrm{~cm}),(\mathbf{B})$ nursery stock 3 months after softwood grafting on 'JM7' apple rootstock (bar = 
Table 6. Molecular biological examination of apple seedlings from 'Prima' $\times$ 95P6 and the parental genotypes.

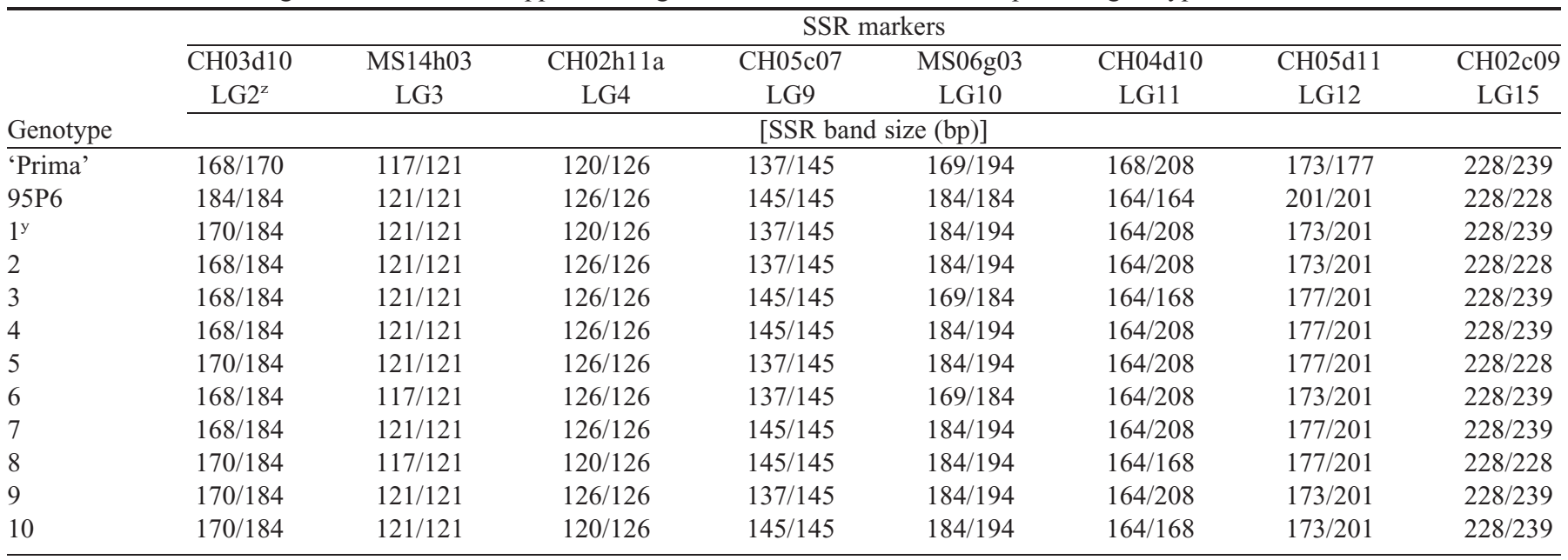

${ }^{\mathrm{z}} \mathrm{LG}=$ linkage group.

'Number of the seedlings obtained from the cross 'Prima' $\times$ 95P6.

tendency of small fruit size in doubled haploids obtained by in situ parthenogenesis was demonstrated by Höfer et al. (2008). Although a statistical comparison of soluble solids and acidity was not conducted, it appears that 95P5 had high soluble solids and low acidity compared with the others.

Evaluation of Male and Female FerTility. The doubled haploids had a significantly reduced number of seeds per fruit compared with that of 'Senshu', but the seed size for 95P6 was similar to that of 'Senshu' (Table 4). The open-pollinated seeds of $95 \mathrm{P} 6$ were viable and the rate of seed germination was $95.0 \%$.

The rate of anther dehiscence of the flowered doubled haploids was dependent on the developmental stage of the flower (Table 5). A later developmental stage tended to increase the rate of anther dehiscence. The fertility of the pollen grains was evaluated by in vitro germination. 'Senshu' showed a pollen germination rate of more than $80 \%$ (Table 5, Fig. 5A), whereas the rate for $95 \mathrm{P} 5$ and $92 \mathrm{P} 3$ was $0 \%$ (Fig. 5, B and C). On the other hand, the pollen germination rate of 95P6 also depended on the developmental stage of the flower. The pollen germination rate at the balloon stage was only $1.3 \%$, but that at the early to middle bloom stage was $20.6 \%$ to $33.0 \%$ (Fig. 5D). These results were rather better than those obtained by Vanwynsberghe et al. (2005) and Höfer et al. (2008) in androgenesis.

To evaluate the reproductive potential of male gametes of 95P6, crosses with 'Prima' apple were carried out. As described above, 95P6 showed considerably later flowering compared with 'Prima'; therefore, hand-pollination was carried out at Morioka, located about $250 \mathrm{~km}$ north of Fukushima. The number of crossing flowers was 150 and after pollination, 24 fruit were set. The efficiency of this result was low at $16.0 \%$ and may have been caused by the small amount of pollen grains of 95P6. In total, 122 seeds were obtained from the fruit and the average number of seeds per fruit was $5.1(\mathrm{SD}=2.7)$. When these seeds were planted in a cell tray with compost, the germination rate was $77.9 \%$, and $81.1 \%$ of the germinated seedlings survived. The seedlings were transferred to an $18-\mathrm{cm}$ polyethylene basin and maintained outside a greenhouse (Fig. 6A). Moreover, parts of these seedlings were grafted onto 'JM7' apple rootstock in the greenhouse (Fig. 6B).
For verification of hybridism of those seedlings, SSR analysis was carried out using eight SSR markers. All of the seedlings showed, with each primer combination, one allele from the maternal parent, and a second allele from the paternal parent (Table 6). This result confirmed that the seedlings were indeed a hybrid between 'Prima' apple and 95P6. All of the other surviving seedlings also had one allele from the maternal parent and a second allele from the paternal parent (data not shown).

In conclusion, the use of homozygous genotypes in apple breeding programs is currently not a realistic approach (Höfer et al., 2008). Homozygous genotypes in apple generally have low vigor, aberrant tree architecture, abnormal flower morphology, and infertility by inbreeding depression (Vanwynsberghe et al., 2005). In the present study, the flowered homozygous genotypes obtained from in vitro culture of anthers of 'Senshu' were confirmed as doubled haploids. One of them, 92P3, showed definitely low vigor, bark morphology comparable with a very old apple tree (similar result reported by Höfer et al., 2008), aberrant flower morphology and pollen infertility, whereas the other genotype, 95P6, showed similar morphological characteristics, except for fruit color, and shape and size of the leaf and fruit compared with the donor genotype 'Senshu', and also produced fertile pollen grains. Moreover, several progenies were obtained from the cross between 'Prima' and 95P6. This progenies grafted onto 'JM7' rootstock are planting in our experimental field. Furthermore, although pollination was open, the female gametes of 95P6 showed slight fertility. Even though several problems arose (e.g., small amount of pollen grains), 95P6 will be used in future studies for breeding and analysis of favorable genes. For the present, we will practice genetic mapping by using the progenies obtained from the cross between 'Prima' and 95P6.

\section{Literature Cited}

De Witte, K. 2000. Review of research at Fruitteeltcentrum on the production of homozygous plants through androgenesis in vitro and parthenogenesis in situ. Acta Hort. 520:135-146.

Gianfranceschi, L., N. Seglias, R. Tarchini, M. Komjanc, and C. Gessler. 1998. Simple sequence repeats for the genetic analysis of apple. Theor. Appl. Genet. 96:1069-1076. 
Guilford, P., S. Prakash, J.M. Zhu, E. Rikkerink, S. Gardiner, H. Bassett, and R. Forster. 1997. Microsatellites in Malus $\times$ domestica (apple): Abundance, polymorphism and cultivar identification. Theor. Appl. Genet. 94:249-254.

Hidaka, T. 1984. Induction of plantlets from anthers of 'Trovita' orange (Citrus sinensis Osbeck). J. Jpn. Soc. Hort. Sci. 53:1-5.

Hidaka, T., Y. Yamada, and T. Shichijo. 1982. Plantlet formation by anther culture in Citrus aurantium L. Jpn. J. Breeding 32:247-252.

Hidano, Y. 1982. Callus and embryoid induction by anther culture of apple. Bul. Fac. Educ. Hirosaki Univ. 48:69-74.

Höfer, M. 2004. In vitro androgenesis in apple: Improvement of the induction phase. Plant Cell Rep. 22:365-370.

Höfer, M., A. Gomez, E. Aguiriano, J.A. Manzanera, and M.A. Bueno. 2002. Analysis of simple sequence repeat markers in homozygous lines of apple. Plant Breed. 121:159-162.

Höfer, M. and V. Hanke. 1990. Induction of androgenesis in vitro apple and sweet cherry. Acta Hort. 280:333-336.

Höfer, M., C. Grafe, A. Boudichevskaja, A. Gomez, and M.A. Bueno. 2004. A comprehensive evaluation of DH-material in apple. Acta Hort. 663:809-813.

Höfer, M., Ch. Grafe, A. Boudichevskaja, A. Lopez, M.A. Bueno, and D. Roen. 2008. Characterization of plant material obtained by in vitro androgenesis and in situ parthenogenesis in apple. Scientia Hort. 117:203-211.

Janick, J., N.C. James, S.K. Brown, and M. Hemmat. 1996. Apples, p. 1-77. In: J. Janick and J.N. Moore (eds.). Fruit breeding. Vol. 1: Tree and tropical fruits. Wiley, New York.

Kadota, M., D.S. Han, and Y. Niimi. 2002. Plant regeneration from anther-derived embryos of apple and pear. HortScience 37:962-965.

Kenis, K. and J. Keulemans. 2000. The use of microsatellites to investigate the homozygous status of apple plants obtained by anther culture and parthenogenesis in situ. Acta Hort. 538:581-585.

Kim, H., H. Kakui, N. Kotoda, Y. Hirata, T. Koba, and H. Sassa. 2009. Determination of partial genomic sequences and development of a CAPS system of the S-RNase gene for identification of $22 S$ haplotypes of apple (Malus $\times$ domestica Borkh.). Mol. Breed. 23:463-472.

Kim, H., J. Park, Y. Hirata, and I. Nou. 2008. Molecular characterization of new $S$-RNases (' $S_{31}$ ' and ' $S_{32}$ ') in apple (Malus $\times$ domestica Borkh.). J. Plant Biol. 51:202-208.

Kim, H.T., G. Hattori, Y. Hirata, D.I. Kim, J.H. Hwang, Y.U. Shin, and I.S. Nou. 2006. Determination of self-incompatibility genotypes of Korean apple cultivars based on S-RNase PCR. J. Plant Biol. 49:448-454.

Kitahara, K., S. Imazu, J. Soejima, and S. Matsumoto. 1997. S-allele genotypes of 15 Malus $\times$ domestica cultivars and partial genomic sequences of $S 2$ and $S 9$ alleles of self-compatible material 'Megumi'. J. Jpn. Soc. Hort. Sci. 66(supplement 1):22-23.

Kitahara, K., S. Matsumoto, T. Yamamoto, J. Soejima, T. Kimura, H. Komatsu, and K. Abe. 2005. Molecular characterization of apple cultivars in Japan by $S$-RNase analysis and SSR markers. J. Amer. Soc. Hort. Sci. 130:885-892.
Komori, S., J. Soejima, K. Abe, N. Kotoda, Y. Ito, and H. Bessho. 2000. Reanalysis of the S-allele genotypes in several apple cultivars. J. Jpn. Soc. Hort. Sci. 69:449-459.

Lespinasse, Y., L. Bouvier, M. Djulbic, and E. Chevreau. 1999. Haploidy in apple and pear. Acta Hort. 484:49-54.

Liebhard, R., L. Gianfranceschi, B. Koller, C.D. Ryder, R. Tarchini, E. Van de Weg, and C. Gessler. 2002. Development and characterization of 140 new microsatellites in apple (Malus $\times$ domestica Borkh.). Mol. Breed. 10:217-241.

Matsumoto, S., K. Kitahara, S. Komori, and J. Soejima. 1999. A new Sallele in apple, ' $S g$,' and its similarity to the ' $S f$ ' allele from 'Fuji'. HortScience 34:708-710.

Matsuno, H., N. Sakuma, and H. Yamaga. 1996. Studies on anther culture of apple and origin of anther-derived plantlets. J. Jpn. Soc. Hort. Sci. 66(supplement 1):593.

Nakayama, R., K. Saito, and R. Yamamoto. 1972. Studies on the hybridization in apple breeding. III. Callus formation and organ differentiation from anther culture. Bul. Fac. Agr. Hirosaki Univ. 19:1-9.

Okada, H., M. Satou, Y. Ohashi, H. Matsuno, S. Takahashi, T. Yamamoto, and S. Komori. 2006. Flower and fruit characteristics of apple doubled haploid from anther culture. J. Jpn. Soc. Hort. Sci. 75(supplement 2):452.

Sakurai, K., S.K. Brown, and N.F. Weeden. 1997. Determining the self-incompatibility alleles of Japanese apple cultivars. HortScience 32:1258-1259.

Silfverberg-Dilworth, E., C.L. Matasci, W.E. Van de Weg, M.P.W. Van Kaauwen, M. Walser, L.P. Kodde, V. Soglio, L. Gianfranceschi, C.E. Durel, F. Costa, T. Yamamoto, B. Koller, C. Gessler, and A. Patocchi. 2006. Microsatellite markers spanning the apple (Malus $\times$ domestica Borkh.) genome. Tree Genet. Genomes 2:202-224.

Vanwynsberghe, L., K. De Wite, E. Coart, and J. Keulemans. 2005. Limited application of homozygous genotypes in apple breeding. Plant Breed. 124:399-403.

Verdoodt, L., A. Van Haute, I.J. Goderis, K. De Witte, J. Keulemans, and W. Broothaerts. 1998. Use of the multi-allelic self-incompatibility gene in apple to assess homozygocity in shoots obtained through haploid induction. Theor. Appl. Genet. 96:294-300.

Yahata, M., S. Harusaki, H. Komatsu, K. Takami, H. Kunitake, T. Yabuya, K. Yamashita, and P. Toolapong. 2005. Morphological characterization and molecular verification of a fertile haploid pummelo (Citrus grandis Osbeck). J. Amer. Soc. Hort. Sci. 130:34-40.

Yamamoto, T., T. Kimura, T. Hayashi, and Y. Ban. 2006. DNA profiling of fresh and processed fruits in pear. Breed. Sci. 56:165-171.

Yoshida, Y., T. Haniuda, H. Bessho, S. Tsuchiya, J. Soejima, T. Masuda, S. Komori, T. Sanada, Y. Ito, S. Sadamori, and Y. Kashimura. 1997. New dwarfing apple rootstock cultivars 'JM 1', 'JM7', 'JM8'. J. Jpn. Soc. Hort. Sci. 66(supplement 1):184-185.

Zhang, Y.X. and Y. Lespinasse. 1991. Pollination with gammairradiated pollen and development of fruits, seeds and parthenogenetic plants in apple. Euphytica 54:101 (Abstr.). 